\title{
IRRITABLE BOWEL SYNDROME AND VOCATIONAL STRESS: INDIVIDUAL PSYCHOTHERAPY
}

\author{
Patricia K Nel \\ MA (RAU) \\ Counselling psychologist

\section{H Gertie Pretorius} \\ D Litt et Phil \\ Professor, Department of Psychology, Rand Afrikaans University \\ Corresponding author: hgpr@lw.rau.ac.za
}

\section{Anita D Stuart \\ D Litt et Phil \\ Professor, Department of Psychology, Rand Afrikaans University}

Keywords: irritable bowel syndrome; stress; life event; vocational stress; psychotherapy.

\begin{abstract}
The goal of this study was to provide individualised psychotherapy for a sample suffering from IBS and vocational stress. A comparison was made between an experimental group of IBS $(N=20)$ participants who received the intervention with a control group of IBS $(N=20)$ participants who received no intervention. The Functional Bowel Disorder Severity Index (FBDSI) and the Occupational Stress Inventory (OSI) were used to determine the severity of their IBS symptoms and the incidence of their vocational stress. Participants fell within the refractory range of IBS symptom severity and between medium to high vocational stress. The study sought to ascertain the effectiveness of holistic individual psychotherapy combined with a synergistic stress management programme in response to the calls for more inclusive and holistic interventions for IBS. This holistic intervention was based on the ecosystemic paradigm which incorporated participants' intra-systemic functioning as well as their wider societal system levels, including family and work subsystems. This intervention appeared to be successful in assisting clients to manage their IBS and their vocational stress.
\end{abstract}

\section{OPSOMMING}

Die doelstelling van hierdie studie was om geïndividualiseerde psigoterapie te verskaf aan 'n steekproef van lyers met Prikkelbare Dermsindroom (PDS) en beroepspanning. ' $n$ Vergelyking is getref tussen 'n eksperimentele groep deelnemers met PDS ( $n=20)$ wat wél die intervensie ondergaan het en ' $n$ kontrolegroep $(n=20)$ met lyers wat geen intervensie ondergaan het nie. Die Funksionele Dermversteuring Erns Indeks (FDEI) en die Beroepspanningsopname is gebruik om die graad van ernstigheid van hul PDS-simptome asook die voorkoms van hul beroepspanning vas te stel. Deelnemers se PDS-simptome het binne die behandelingstrae reikwydte geval en daar is vasgestel dat hulle beroepspanning tussen medium tot hoog was. Die studie poog om die effektiwiteit van holistiese individuele terapie, gekombineer met 'n sinergistiese stresbeheerprogram, te bepaal in respons op die huidige soeke na 'n inklusiewe holistiese intervensie vir die behandeling van PDS. Hierdie holistiese intervensie is gebaseer op 'n ekosistemiese paradigma wat die deelnemer se intrasistemiese funksionering asook sy/haar wyer gemeenskapsisteemvlakke, insluitend gesin en werksubsisteme, inkorporeer. Dit wil voorkom asof hierdie intervensie die kliënte help om hulle PDS en beroepspanning suksesvol te beheer. 


\section{INTRODUCTION}

Both Irritable Bowel Syndrome (IBS) and stress have been described as lifestyle disorders which are prevalent and gaining increasing awareness in this modern era, particularly within developed countries (Drossman, 1998:200; Salt, 1997:50; Sapolsky, 1994:61). Whilst growing attention is being devoted to both of these problems, the relationship between IBS and stress is not new but has been recorded since early civilisation. It is only recently, however, that a more complex discussion of this relationship is beginning to elucidate the concepts and the mechanisms that may be necessary to understand this as a truly psychosomatic (mind-body) health problem.

There is currently a resurgence of experimental and theoretical interest in stressful experience, which is implicated in many diseases, disorders and lifestyle problems today. Stress either causes or exacerbates these conditions which frequently result from a slow accumulation of symptoms due to the modern style of living. According to Sapolsky (1994:65-67), there has been a critical shift in medicine which now recognises the complex intertwining in man's biology and mind, including emotions and cognitions, in response to stressful experiences. Stress has been implicated in all the functional disorders of the gastrointestinal tract (Drossman, 1994:56) and IBS is the specific psychosomatic illness examined here.

IBS is defined as a functional bowel disorder in which abdominal pain is associated with defaecation or a change in bowel habit and abdominal distension (Drossman, 1994:60). It is highly prevalent in the Western world with epidemiological surveys indicating approximately one fifth of the population suffers from one or more gastrointestinal symptoms (Drossman, Thompson \& Whitehead, 1992:175). Many do not seek medical attention, however IBS constitutes $25-50 \%$ of referrals to gastroenterologists (Drossman, 1994:70). Due to the unexplained etiology and the ineffectiveness of treatment modalities, IBS sufferers are invariably subjected to costly and invasive diagnostic procedures and medical care. Studies now show that the costs are considerable each year in visits to doctors, diagnostic testing, treatment and work absenteeism, with IBS ranking second only to the common cold (Els, Gagiano, Grundling, Van Zyl \& Joubert, 1995:1368;
Salt, 1997:55).

The etiological factors that combine IBS with stress have frequently been studied in experimentally acute episodes that may not reflect the often chronic nature of this disorder. Stress has been studied directly but often the associations are made indirectly by inference and there is still much to be discovered about its relationship with IBS. The specific areas studied directly or indirectly include experimental stress effects on intestinal motility, visceral hypersensitivity and autonomic nervous system or 'brain-gut' connection as well as a number of facets of life event stress, illness beliefs, personality traits, psychopathology and social resources. Many of these effects are interactive but have been examined separately.

The life event examined in this study is vocational stress as an ongoing source of stress. The term vocational was used rather than work or occupation, to broaden the definition to include both paid and unpaid work in the form of family work, volunteer and community work (Richardson, 1993:425). Modern researchers are beginning to differentiate between underlying chronic stress responses which occur in childhood to those which are acute episodes occurring in ongoing life events (Kelly, Hertzman \& Daniels, 1997:437). It is recognised that life events, as ongoing processes, contain both objective and subjective measures (Kimball, 1984:56; Lazarus \& Folkman, 1984:42). The basis of the resultant life stress depends on the individual's innate capacity, previous or present learned coping style and other personality attributes or resources. Objectively, stress is perceived as a social or environmental event or as an event that is externally induced. However, what is identified by an individual as stress, either consciously or unconsciously, may lead to feelings of distress that is largely then an internal psychological and subjective experience. According to Kimball (1984:57), this experience of a life event involves a number of factors which are dependent on the individual's internal processes which include an intactness of cognitive functions such as orientation, capacity for arousal, memory, concentration and affective stability. Implicit in Kimball's (1984:57) usage of internal processes is both physiological arousal and emotional content. It is clearly evident that to view life events as merely external to and impinging on the person without tak- 
ing into account the mind-body effects within the person, is to deny or distort the reality as it is experienced by many people currently suffering from IBS.

This study examined the practical aspects of having to care for and treat persons with IBS and stress. Despite the acknowledgement that IBS is truly a biopsychosocial phenomenon, examination of the literature reveals that treatment strategies tend to focus on either the biological or the psychological. Schlebusch (1990:30) maintains that physicians still primarily treat the emotional and cognitive aspects physically or psychologically. Approaches to treatment from within the medical profession have varied from single treatments for specific symptoms, to multicomponent treatments with various guidelines (Drossman, 1994:45; Drossman, Thompson \& Whitehead, 1992:183). In view of the advances in molecular biology and the theory of the communication amongst the various systems of the body, new mindbody strategies are evolving, although the processes linking the body and the mind have not as yet been elucidated (Farthing, 1995:171; Pert, Ruff, Weber \& Herkenham, 1985:820s). Treatments tend to focus on end or central organ interventions, which include a variety of psychotherapeutic treatments.

Recently, a more integrative holistic perspective has been advocated where Drossman, Whitehead and Camilleri (1997:2120) have begun to consider the individualised expression of the illness in the patient. They have begun to situate the patient in his/her wider social systems, as well as incorporating a referral team approach to the treatment of IBS. Salt (1997:55) has extended the biopsychosocial model to include the spiritual dimension in his treatment of IBS patients whilst Broom (1997:47) weaves the various internal systems of the person into the story of the client's illness that integrates the mind and body.

Treatment of IBS through psychological interventions has had consistently encouraging results (Bennett, 1989:51) and from a summary of treatments, all were found to be superior to gastrointestinal symptom monitoring and pharmacological medical care alone (Blanchard, 1993:79). Treatments have also ranged from single treatments to multi-component treatments and have included a variety of psychotherapies, hypnotherapy, biofeedback and stress management techniques. Integrative efforts in psychological practices and models of caring propose understanding the person's physical and psychological behaviour within multiple levels.

As the field of behavioural medicine and psychological healthcare moves more directly into integrative endeavours, the research question asked in this study is whether utilising an individualised holistic psychotherapy and synergistic stress management programme for the treatment of clients with IBS symptomatology and vocational stress will be successful. Will it in some way contribute to the humane treatment of persons who suffer from this debilitating disorder?

\section{RESEARCH PROBLEM}

Since Schwarz, Blanchard, Berreman, Scharff, Taylor, Greene, Suls and Malamood (1993:297) reviewed the literature on stress and IBS and observed that IBS patients are almost unanimously described as psychologically distressed, psychological treatment strategies for IBS have invariably included relaxation techniques and cognitive therapies for distress (Blanchard, 1993:72). There is, however, no indication in the available literature of a psychotherapeutic intervention that adopts a fully integrated metatheoretical approach to the treatment of IBS and stress.

The present study not only responds to the call for more integrative individualised treatment approaches to IBS but also includes the rationale for holistic approaches which in psychology necessitates the inclusion of a meta-theoretical framework (Clarkson, 1996:64). The ecosystemic paradigm is the metatheoretical framework for this study in which the intervention targets the intra-systemic functioning within the various subsystems of the individual, namely the cognitive, emotional, behavioural, physiological and spiritual subsystems, as well as the wider social systems, including the family as well as the occupational subsystem. Included in this holistic approach, clients were trained in a combination of stress management techniques, which targeted both the body and the mind as recommended by leading stress researchers Lehrer and Woolfolk (1993:40). The specific research question asked in this study is whether there are statistically significant differences 
between IBS clients who receive an individualised holistic intervention and synergistic stress management programme and those who do not, in terms of the severity of their symptoms and also their vocational stress.

\section{AIMS OF RESEARCH}

This research project forms part of a broader project initiated in 1996 by the Counselling and Research Centre for Psychogastroenterology of the Rand Afrikaans University in Johannesburg. The aim of the project was to approach the study of IBS from the standpoint of psychology and to contribute to the understanding of the psychosocial dimensions of this illness. A second phase of this research project was to develop and provide psychotherapy for the participants in the form of three interventions, namely a holistic individual psychotherapy; a holistic individual and stress management psychotherapy; and a holistic group psychotherapy.

This study had two broad aims. Firstly, to respond to the call from integrative medicine and behavioural health psychology for more holistic treatment approaches to IBS and stress. Secondly, the question asked by researchers is whether psychotherapy is effective for refractory IBS sufferers. As the entire sample in this study fell within the range of symptom severity diagnosed as severe or refractory, an additional aim was to confirm the findings of Guthrie, Creed, Dawson and Tomenson (1991:450; 1993:315) that severe or refractory IBS patients can be helped with psychotherapy.

The study seeks to ascertain the effectiveness of a holistic individual psychotherapy combined with a synergistic stress management programme in a sample of IBS participants who received the intervention and to compare them with a control group of IBS participants who received no intervention. Therefore the specific operationalised aim of the study was firstly to establish whether there are statistically significant differences between two groups of participants with IBS ( $\mathrm{N}=20$ in each group) with regard to the severity of their pre- and post-test IBS scores, as measured by the Functional Bowel Disorder Severity Index (FBDSI) (Drossman, Zhiming, Toner, Diamant, Creed, Thompson, Read, Babbs, Barreiro,
Bank, Whitehead, Schuster \& Guthrie, 1995:986). Secondly the differences between the two groups in terms of their vocational stress scores as measured by the three scales of the Occupational Stress Inventory (OSI) (Osipow \& Spokane, 1987:7), namely the Occupational Roles, Personal Strain and Personal Resources Inventories respectively have to be ascertained.

\section{HYPOTHESES}

The following four main alternate research hypotheses were identified:

- Hypothesis 1: Pre-tests for Group 1 (IBS Intervention) versus Group 2 (IBS NonIntervention)

- Hypothesis 2: Post-tests minus pre-tests for Group 1 (IBS Intervention) versus Group 2 (IBS NonIntervention)

- Hypothesis 3: Pre-tests versus post-tests for Group 1 (IBS Intervention)

- Hypothesis 4: Pre-tests versus post-tests for Group 2 (IBS Non-Intervention).

Each of these hypotheses consist of the following four composite hypotheses, which establish whether differences exist between the experimental (IBS Intervention) group and the control (IBS NonIntervention) group, and between pre- and post-tests for the two groups:

1. There is a statistically significant difference in the averages of the FBDSI.

2. There is a statistically significant difference in the vector of averages of the six subscales, of the Occupational Roles scale of the OSI.

3. There is a statistically significant difference in the vector of averages of the four subscales, of the Personal Strain scale of the OSI.

4. There is a statistically significant difference in the vector of averages of the four subscales of the Personal Resources scale of the OSI.

\section{METHOD}

\section{Sample}

IBS sufferers were invited to participate in the broader research project of the Counselling and Research Centre for Psychogastroenterology and were recruited 
in several ways. Doctors in general practice and specialist gastroenterologists, were invited by letter from the Counselling and Research Centre at the Rand Afrikaans University to refer patients positively diagnosed with IBS to the Centre. An article on IBS was published in the Medical Chronicle, a local popular women's magazine, and advertisements were placed in Johannesburg newspapers inviting participation in the project. Individuals expressing interest were required to obtain a doctor's referral confirming their diagnosis of IBS and ruling out organic pathology.

Two groups were selected for the purpose of the present research project, namely an experimental group of IBS participants who were to receive a psychotherapeutic intervention and a control group of IBS participants who would not receive an intervention. The experimental group was chosen on the basis of the results of the questionnaires from the wider group of participants who responded to the aims of the broader Psychogastroenterology project described above. A sample of twenty $(\mathrm{N}=20)$, comprising sixteen women and four men, were selected for the purposes of this study and this was equitable with the ratio of women to men who responded to the project. The control group, on the other hand, were recruited differently, through dieticians, a homeopath and a network of contacts among associates. The primary requirement was that the controls had been diagnosed with IBS and had not received psychotherapy for their IBS. Twenty $(N=20)$ participants were selected, in the same ratio of women to men as the experimental group in order to maintain the homogeneity of the groups. Both groups had scores in excess of 111 for their IBS and therefore fell within the refractory range of IBS (Drossman et al. 1995:986) and their occupational stress scores fell between medium to high stress.

Table 1 provides more information on the two groups in terms of the various background variables that were regarded as possibly relevant.

The respondents for the broader Psychogastroenterology project were predominantly white, consequently race was controlled and only white participants were included in this study. Only two of the language groups in South Africa were represented, being English- and Afrikaans- speaking participants. As is evidenced by the comparisons in Table 1, a high degree of homogeneity between the groups was maintained.

Table 1: Description of the IBS Experimental and Control Group

\begin{tabular}{|l|l|l|}
\hline & $\begin{array}{l}\text { Experimental (Intervention) } \\
\text { Group } \\
\mathbf{N}=\mathbf{2 0}\end{array}$ & $\begin{array}{l}\text { Control (Non- } \\
\text { Intervention) Group } \\
\mathbf{N}=\mathbf{2 0}\end{array}$ \\
\hline AGES & 10 & 5 \\
$20-39$ & 10 & 15 \\
$40-70$ & 16 & \\
\hline GENDER & 4 & 16 \\
Female & & 4 \\
Male & 4 & \\
\hline EDUCATIONAL LEVEL & 4 & 0 \\
< Matric & 12 & 9 \\
Matric & & \\
> Matric & 4 & 2 \\
\hline MONTHLY INCOME & 9 & 6 \\
R0 - R1 999 & 7 & 12 \\
R2 000 - R5 999 & & \\
> R6 000 & & \\
\hline
\end{tabular}




\section{Methods of data collection}

Two measuring instruments were selected to obtain pre-test and post-test scores.

\section{The Functional Bowel Disorder Severity Index (FBDSI)}

This is a standardised scoring system that is described in the literature as a measure of the nature and severity of Functional Bowel Disorders. Due to the lack of an available objective measuring instrument specifically for IBS, it was decided to use the Functional Bowel Disorder Severity Index (FBDSI) in order to obtain a single quantifiable score for the measurement of severity of IBS (Drossman et al. 1995:987). Based on Drossman et al.'s (1995:988) research, three levels of severity are apparent. The cut-off scores being less than 36 for mild illness, 37-110 for moderate illness, and over 111 for severe illness. Only those with severe symptoms participated in this research project.

Drossman et al. (1995:990) provide evidence which attests to the reliability of the FBDSI, based on visual analogue scales and test-retest reliability. Validity has also been determined in terms of face and convergent validity by means of regression analysis.

\section{The Occupational Stress Inventory (OSI)}

Osipow and Spokane (1987:10) found that there are satisfactory levels of consistency and test-retest reliability. The alpha coefficients for the total questionnaire scores were .89 (ORQ), .94 (PSQ), and $.99(P R Q)$. Coefficients for the 14 individual scales ranged from .71 to .94 . Satisfactory validity coefficients were also obtained from factor analytic studies and correlational studies.

In the South African context, this inventory has been used by Bayne (1997:106-110) and by Bayne, Stuart and Pretorius (1999:22).

\section{STATISTICAL ANALYSIS OF DATA}

Wilks' Lambda was used to determine whether the vectors of averages between the two groups (the IBS Intervention group versus the IBS Non-Intervention group) differ statistically from one another with regard to the scores on the FBDSI. Also, with regard to the various subscales of the three scales of the OSI; namely the Occupational Roles, Personal Strain and Personal Resources scales. The Paired Samples ttest was used to determine whether there are withingroup (as opposed to between-group) differences with regard to the pre- versus post-intervention test scores for Group 1 and then also for the pre- versus post-test scores for Group 2 without an intervention.

\section{RESULTS}

From pre-treatment to post-treatment, participants in the psychological treatment group showed greater clinical improvement than the control group with a reduction in symptom severity and occupational stress and a higher utilisation of coping resources. On the pre- and post-test evaluations of the non-treatment group, symptom severity on the FBDSI remained unchanged and on 13 of the 14 subscales of the OSI no significant change had occurred, with the one exception of Role Boundary which appeared to have worsened. An interpretation of this last result is that without receiving a therapeutic intervention, participants in the control group of the research project showed no improvement in their symptom severity and occupational stress.

\section{Results of Hypothesis 1}

There are no statistically significant differences between Group 1 (IBS Intervention) and Group 2 (IBS Non-Intervention) in terms of the pre-tests of the FBDSI $(p=0,222)$. The results indicate that the two groups were equal in the severity index prior to the holistic intervention.

There are no statistically significant differences between Group 1 (IBS Intervention) and Group 2 (IBS Non-Intervention) in terms of the pre-tests of the Occupational Roles' six subscales of the OSI when taken together (Wilks' Lambda $\mathrm{p}=0,072$ ). Accordingly the t-test for the equality of means were not interpreted. The results indicate that the two groups were equal in the Occupational Roles' six subscales when taken together, prior to the holistic intervention.

There are no statistically significant differences between Group 1 (IBS Intervention) and Group 2 (IBS Non-Intervention) in terms of the pre-tests of the Personal Strain's four subscales of the OSI (Wilks' 
Lambda $p=0,566)$. The results indicate that the two groups were equal in the Personal Strain's four subscales when taken together, prior to the holistic intervention.

There are no statistically significant differences between Group 1 (IBS Intervention) and Group 2 (IBS Non-Intervention) in terms of the pre-tests of Personal Resources' four subscales of the OSI (Wilks' Lambda $p=0,901)$. The results indicate that the two groups were equal in the Personal Resources' four subscales when taken together, prior to the holistic intervention.

\section{Results of Hypothesis 2}

There are statistically significant differences between the post-tests minus the pre-tests of Group 1 (IBS Intervention) and Group 2 (IBS Non-Intervention) regarding the FBDSI $(p=0,003)$. Group 1 , on average, improved more $(m=-48.05)$ than the non-intervention group $(m=-3.80)$. A negative value indicating an improvement, that is, the pre-test value is larger than the post-test value.

There are statistically significant differences between the post-tests minus the pre-tests for Group 1(IBS Intervention) and Group 2 (IBS Non-Intervention) regarding the six subscales of the Occupational Roles scale of the OSI taken together (Wilks' Lambda $p<$ $0,001)$. The results of the t-test for equality of means indicate that the differences are in terms of four of the six subscales. Role Overload ( $p=0,008 ; m$ Group $1=$ $-2,450 ; m$ Group $2=1,150)$, Role Insufficiency $(p=$ 0,001; $m$ Group $1=-3,200 ; m$ Group $2=2,050$ ), Role Boundary ( $p=0,000 ; m$ Group $1=-3,700 ; m$ Group 2 $=2,750)$ and Role Responsibility ( $p=0,015 ; \mathrm{m}$ Group $1=-2,250 ; m$ Group $2=6,000)$. The results indicate that the averages in four of the six subscales of the Occupational Roles' scale in the experimental group have improved significantly after completion of the holistic intervention. There are no statistically significant differences between the post-tests minus the pre-tests for Group 1 (IBS Intervention) and Group 2 (IBS Non-Intervention) regarding Role Ambiguity ( $p$ $=0,093)$ and Physical Environment $(p=0,312)$.

There are statistically significant differences between the post-tests minus the pre-tests for Group 1 (IBS Intervention) and Group 2 (IBS Non-Intervention) re- garding the four subscales of the Personal Strain scale of the OSI taken together (Wilks' Lambda $p=0,006$ ). The results of the t-test for the equality of means indicate that the differences are in terms of all four subscales. Vocational Strain $(p=0,001 ; m$ Group $1=$ $-3,650 ; m$ Group $2=0,250)$, Psychological Strain $(p=$ 0,024; $m$ Group $1=-4,700 ; m$ Group $2=-0,800)$, Interpersonal Strain ( $p=0,011 ; m$ Group $1=-3,000 ; m$ Group $2=-0,100)$ and Physical Strain $(p=0,010 ; m$ Group $1=-4,050 ; m$ Group $2=0,300)$. The results indicate that all four of the subscales of the Personal Strain scale in the experimental group have improved significantly after completion of the holistic intervention, that is, the post-test score was less than the pretest score.

There are statistically significant differences between the post-tests minus the pre-tests for Group 1 (IBS Intervention) and Group 2 (IBS Non-Intervention) regarding the four subscales of the Personal Resources scale of the OSI taken together (Wilks' Lambda $p=$ $0,004)$. The results of the t-test for the equality of means indicate that the differences are in terms of all four subscales. Recreation ( $p=0,002 ; m$ Group $1=$ $5,110 ; m$ Group $2=0,250)$, Self-Care $(p=0,002 ; m$ Group $1=5,350 ; m$ Group $2=0,500)$, Social Support $(p=0,022 ; m$ Group $1=4,150 ; m$ Group $2=-0,350)$ and Rational/Cognitive Coping ( $p=0,000 ; \mathrm{m}$ Group 1 $=4,600 ; \mathrm{m}$ Group $2=-0,200)$. The higher average post-test scores of the experimental group indicate greater Personal Resources are utilised in all four subscales after completion of the holistic intervention.

\section{Results of Hypothesis 3}

There are statistically significant differences between the pre-tests and the post-tests of Group 1 (IBS Intervention) regarding the FBDSI $(p=0,001)$. The average post-test score $(m=145,20)$ has reduced significantly from the average pre-test score $(m=193,25)$ in the experimental group indicating improvement in the severity index after completion of the holistic intervention.

There are statistically significant differences between the pre-tests and the post-tests for Group 1(IBS Intervention) on four of the six subscales of the Occupational Roles scale of the OSI. Role Overload $(p=0,032 ; m$ pre-test $=30,20 ; m$ post-test $=27,75)$, 
Role Insufficiency $(p=0,009 ; \mathrm{m}$ pre-test $=29,40 ; \mathrm{m}$ post-test $=26,20)$, Role Boundary $(p=0.013 ; \mathrm{m}$ pretest $=27,70 ; \mathrm{m}$ post-test $=24,00)$ and Role Responsibility ( $p=0,036$; $\mathrm{m}$ pre-test $=29,50$; $\mathrm{m}$ posttest $=27,75$ ). The results indicate that the averages in four of the six subscales of the Occupational Roles' scale in the experimental group are significantly lower after completion of the holistic intervention suggesting that the intervention was successful. There were no statistically significant differences between the pretests and the post-tests for Group 1 (IBS Intervention) regarding Role Ambiguity $(p=0,162)$ and Physical Environment $(p=0,121)$.

There are statistically significant differences between the pre-tests and the post-tests for Group 1 (IBS Intervention) on all four subscales of the Personal Strain scales of the OSI. Vocational Strain $(p=0,001$; $\mathrm{m}$ pre-test $=23,95 ; \mathrm{m}$ post-test $=20,30$ ), Psychological Strain $(\mathrm{p}=0,004$; $\mathrm{m}$ pre-test $=33,05 ; \mathrm{m}$ post-test $=$ $28,35)$, Interpersonal Strain $(p=0,006$; $m$ pre-test $=$ 27,95; $\mathrm{m}$ post-test $=24,95)$ and Physical Strain $(p=$ $0,011 ; \mathrm{m}$ pre-test $=30,75 ; \mathrm{m}$ post-test $=26,70)$. The results indicate that the averages of all four of the subscales of the Personal Strain scale in the experimental group are significantly lower after completion of the intervention suggesting that the intervention was successful.

There are statistically significant differences between the pre-tests and the post-tests for Group 1 (IBS Intervention) on all four subscales of the Personal Resources scales of the OSI. Recreation ( $p=0,001 ; m$ pre-test $=23,85 ; m$ post-test $=28,95)$, Self Care $(p=$ 0,$001 ; \mathrm{m}$ pre-test $=22,45 ; \mathrm{m}$ post-test $=27,80$ ), Social Support $(p=0,032$; $m$ pre-test $=36,25$; $\mathrm{m}$ posttest $=40,40)$ and Rational/Cognitive Coping $(p=0,000$; $\mathrm{m}$ pre-test $=31,40 ; \mathrm{m}$ post-test $=36,00)$. The higher post-test scores for the experimental group indicate that greater Personal Resources are utilised in all four subscales after completion of the holistic intervention suggesting the intervention was successful.

\section{Results of Hypothesis 4}

There are no statistically significant differences between the pre-test versus post-test of Group 2 (IBS Non-Intervention) regarding the FBDSI $(p=0,593)$. The results indicate that there were no significant differences in the averages of the control group from the pre-test $(m=174,70)$ to the post-test $(m=170,90)$ suggesting that when receiving no intervention, there was no improvement in the severity index.

There were no statistically significant differences between the pre-test versus post-test for Group 2 (IBS Non-Intervention) regarding the five subscales of the OSI, namely Role Overload, Role Insufficiency, Role Ambiguity, Role Responsibility and Physical Environment $(p>0,05)$. There was a statistically significant difference regarding Role Boundary only $(\mathrm{p}$ $=0,003 ; \mathrm{m}$ pre-test $=22,55 ; \mathrm{m}$ post-test $=25,30$. The results indicate that the averages in five of the six subscales of the Occupational Roles' scale in the control group did not improve significantly without any intervention. Role Boundary appeared to worsen with the post-test average ( $m=25,30$ ) being significantly higher than the pre-test average $(m=22,55)$.

There were no statistically significant differences between the pre-test versus the post-test for Group 2 (IBS Non-Intervention) on any of the four subscales of the Personal Strain scale of the OSI, namely Vocational Strain, Psychological Strain, Interpersonal Strain and Physical Strain ( $p$-values $>0,05$ throughout). The results indicate that the averages in the four subscales of the Personal Strain scale in the control group did not improve significantly without any intervention.

There were no statistically significant differences between the pre-test versus the post-test for Group 2 (IBS Non-Intervention) on any of the four subscales of the Personal Resources' scale of the OSI, namely Recreation, Self-Care, Social Support and Rational/ Cognitive Coping ( $p$-values $>0,05$ throughout). The results indicate that the averages in the four subscales of the Personal Resources' scale in the control group did not improve significantly without any intervention.

The results presented in this study indicate that statistically significant differences exist between the IBS group that received a therapeutic intervention and the IBS group that received no therapeutic intervention. Even so, a limitation of this study would be that a large number of hypotheses were tested and as such, some of the observed significant differences may be spurious. Also, the number of respondents $(n=20$ in 
each group) is small.

\section{DISCUSSION}

The intervention conducted in this project attempts to answer the call for more holistic approaches to the treatment of IBS. It reflects the move to integrative postmodernistic solutions to the psychosomatic illness of IBS. A strength of this holistic intervention is that it followed the guidelines given by the integrative movement in psychology. It differentiates between the haphazard addition of parts of different theoretical and therapeutic perspectives to the inclusion of a metatheoretical conceptual framework where the whole is more than the sum of the parts (Norcross \& Grencavage, 1990:44). This enables the therapist to systematically apply relevant therapies and then integrate them into a pragmatic therapeutic application for the client, guided by theoretical considerations (Baruth \& Huber, 1985:53).

The meta-theoretical integrative framework for this intervention is based on the ecosystemic paradigm. It targets the intra-systemic functioning within the various subsystems of the individual, namely the cognitive, emotional, behavioural, physiological and spiritual subsystems, as well as the wider inter-systemic social systems including the family and the occupational subsystem (O'Connor \& Lubin, 1984:64).

Whilst all of these systems were addressed in the therapeutic encounter, special mention is made of only those subsystems which stood out and required specific work in order to bring the client back into balance. Balance is one of the basic tenets of ecosystemic philosophy (Keeney, 1983:33). Where this confirms previous findings within the research literature, a statement is made to that effect.

\section{Emotional subsystem}

Several studies have highlighted the importance of examining the emotional intra-subsystem of the IBS client and have noted the difficulty experienced by clients in moving from the somatic to the feeling expression of their illness, including this present study (Bush, 2001:78; Dolan, 2000:90; Lammert \& Ratner, 1987:67). The research literature supports the view that clients have difficulty in learning to 'feel' appropri- ately. They also have difficulty in finding the right words to convey the meaning of the visceral sensations they are experiencing or their personal feelings and that they resort to metaphoric and somatic expression or somatisation (Lammert \& Ratner, 1987:67; Watkins, 1995:283). This subsystem required a considerable amount of time spent on training clients to recognise their emotions and to name them accurately. With the attention given to this aspect of their functioning, clients frequently experienced intense and very difficult emotions.

It is recognised that the emotional component of IBS which is expressed in the present time by stories of life event stress which bring the patients to the physician for their pain, often mask buried and forgotten emotional traumas (Whitfield, 1995:29). In this study, the literature on sexual and physical abuse was supported in that buried memories of this abuse were 'remembered' and relived (Whitfield, 1995:32) in order for clients to move beyond their pain. However many subtle forms of emotional neglect can also result in deeply buried parts of self. A clinical observation of the intervention group in this study indicated that eighteen out of the twenty clients were experiencing various degrees of traumatic memory and that in all of these cases their IBS had been chronic and long-lasting. It would appear in this research that once the buried emotions had surfaced and been integrated, that some of the pain and IBS symptomatology was lessened.

The remaining two clients had been experiencing IBS from between two to four years and had a very specific stressful life event to which they could link the onset of their IBS. Once these specific life event issues had been dealt with, both also experienced immediate relief from their IBS symptoms. These two clients could be defined as 'acute' sufferers, whereas the other eighteen were 'chronic' sufferers from childhood. Working with the emotional intra-subsystem of the client proved to be extremely important in the treatment of IBS and stress.

\section{Cognitive subsystem}

Another intra-subsystem that proved important to restructure was the cognitive subsystem. One of the hypotheses in the psychosomatic communication 
model (Pert et al. 1985:821s; Watkins, 1995:283) is that from early childhood, various illness systems of the body (like the gastrointestinal system) may have a genetic vulnerability. These systems are recruited by the various stress physiology systems so that illness or stress triggers a response in these systems simultaneously. Watkins (1995:284) found evidence linking the higher cognitive and limbic centres with psychological and emotional states. Greene and Blanchard (1994:576) found that the relation between GI symptoms and changes in automatic cognitions was so interdependent that they hypothesised that the cognitive-physiological association might be a reciprocal or circular one. When clients in this study were able to address their emotional issues, they were able to re-align their cognitions with their new perspective. This enabled them to make new choices about their health and their lifestyles, including decisions on problems that were interfering with the success in their relationships and their work.

This study supports the findings by Gomborone, Dewsnap, Libby and Farthing (1993:1230) that the client's negative self-schema incorporate themes of physical illness and beliefs about illness, rather than those of worthlessness and guilt that are characteristic of depression. The clients of this study's distress was being manifested in the soma as physical symptoms, they also utilised Beck's (1976:40) full range of 'mustabatory' thoughts. The use of catastrophising cognitions showed themselves to have perfectionistic streaks and rigid thinking which fits with the personality characteristics IBS clients are purported to have (Latimer, 1983:205; Stanley, 2000:63; Van Dulmen, Fennis, Mokkink, Van der Velden \& Bleijenberg, 1994:581).

One of the scales on the OSI, which consistently did not change was Role Ambiguity. The literature review indicated that IBS sufferers tend to have personality characteristics of rigidity, obsessive-compulsive traits including conformity and rituals, orderliness and perfectionism (Latimer, 1983:206). They have higher levels of reactivity to change, emotional distress and negative emotions, and are also more prone to irrational and disturbed thoughts and behaviours that accompany this distress (Stanley, 2000:65). An inference that could be drawn from this is that when faced with ambiguous and unclear directions in terms of the roles they need to perform, they would experience higher stress. Therefore IBS sufferers were required to open their belief systems (Benson, 1996:59), including their coping responses of denial (Lazarus, 1993:61) and escape-avoidance (Bekker, Hentschel \& Reinsch, 1993:142), to include newer and different ways of approaching their lives.

\section{Relationship difficulties in the occupational subsystem}

This interpersonal subsystem evokes the relationship between the individual as a whole system and his/her wider systems such as the family and the occupational subsystem. These two subsystems appeared to overlap. One of the main clinical observations was the theme that problems defined as 'work-related', were actually relationship problems. It may be that clients needed to challenge an unfair boss, or to redefine their roles in the workplace with a co-worker, or that their home relationship problems spilled over into the work situation. Frequently their stress was linked to role boundary problems and lack of support. This highlights the interactive effects between the various facets of work roles and the different forms of personal and psychological strains the client was experiencing. Current ecological stress theories view human beings as embedded within networks of relationships and deeply bonded to and affected by significant persons in their social environment (Bowlby, 1969:38; Weiner, 1992:61). As clients began to utilise more coping resources, they appeared to cope more effectively with their IBS and with their occupational stress.

\section{Relationship between therapist and client}

This study affirms the statement by Sanders (1996:25) that clients suffering from psychosomatic disorders need a period of adjustment to being in psychotherapy in order to build a relationship with the psychologist. Diagnosis was therapeutic as it offered a name with which clients could identify their disorder, as well as a rationale for the symptoms being experienced. It was used as part of the development of the therapeutic relationship and as education about IBS as well as a means of showing positive regard for the clients (Sanders, 1996:30). By providing the clients with psychoeducation about the psychological components of their disorder, they were assisted to feel empow- 
ered within the process. They could begin to move from a position of inequality to viewing themselves as partners in the process (Drossman et al. 1997:2121; Lammert \& Ratner, 1987:69; Salt, 1997:30). This accords with the postmodernistic idea of partnerships in health seeking between the professional and the client (Drossman et al. 1997:2120; Salt, 1997:31).

Common sense dictates that the therapist and the client must inevitably impact on one another as human beings. Satir (Loeschen, 1998:15) views therapy as providing the context for the deepest self of the therapist to meet the deepest self of the client and she considers this aspect as an essential factor in the therapeutic process. Apart from the use of counselling micro skills, clients need to encounter the humanity of the therapist in the form of compassion, being present in the here and now and the psychological congruency of the therapist which all impact on the client within the therapeutic encounter (Egan, 1994:46). Whilst this is an entirely subjective evaluation of what occurred in this project, nevertheless research indicates that the use of the self of the therapist needs to be considered as having contributed to the success of the intervention.

\section{The non-intervention group did not change}

The group that did not receive the intervention did not improve in terms of the severity of their IBS symptoms, nor did their occupational stress and psychological strain go down, nor did they utilise more resources. Only one subscale, Role Boundary, showed a significant difference in this group and in fact worsened. One inference from this could be that the filling in of psychometric forms and contact with a therapist might have created ambiguity. By considering that psychological components could be part of their illness, which the majority of the non-intervention group had not previously considered, it could have influenced them to begin to consider this option. They were offered psychotherapy in the future once their post-tests were completed. Another possible attributory factor is the fact that a large number of hypotheses were tested. Hence, some spurious significant results should occur.

\section{LIMITATIONS}

Methodological shortcomings and limitations that were encountered in this study include a lack of randomisation in the selection of the control and experimental groups. It was necessary to select the sample based on availability, and thus the two groups were chosen differently. This sample is thus not representative of the population. The sample size of 20 in each group (control and experimental) is small, and as such, the interpretations for this study with regard to improvement of symptoms and stress should probably be used in a cautionary manner. Only partial blinding was ensured in this study in terms of patientto-group allocators, trial managers and outcome assessors.

\section{CONCLUSION}

Research has not yet proved conclusively whether stress causes, mediates or in fact whether it is correlated at all with IBS. The nature of the relationship between stress and illness is a complex one, the mechanisms of which are not as yet fully understood. Clearly in some situations, the relationship is causal as stressful events exert direct effects resulting in illness. In other circumstances stress may be a cofactor, predisposing the individual to illness. Another way in which the relationship could be conceptualised is that illness itself causes greater stress throughout a person's relationships and life experiences. It is also quite probable in fact that both stress and illness are not related at all but are rather both expressions of a general vulnerability existing in a person towards IBS (Williams, Zyzanski \& Wright, 1992:763).

Although no outcome studies were conducted to assess whether clients continued to show improvement of their IBS symptoms as well as their stress, the conclusion is drawn that both broad aims of the study were achieved. Firstly that a metatheoretical ecosystemic psychotherapeutic intervention that combined individualised holistic psychotherapy and synergistic stress management programme of this specific study did what it set out to do. It helped people to manage their IBS and their lives. It affords a very specific and definite place for the psychologist in the treatment of psychosomatic illnesses. Through triggering traumatic memories, recognition of emotions and themes of illness and beliefs, balanced with expectancy of wellness, IBS symptom severity and 
stress was reduced in a group of IBS sufferers and improved coping resources were utilised. Secondly, the question asked by researchers as to whether psychotherapy was effective for refractory IBS sufferers appears to confirm the findings to that effect by Guthrie et al. (1991:451, 1993:316).

\section{REFERENCES}

BARUTH, LG \& HUBER, CH 1985: Counselling and psychotherapy: Theoretical analyses and skills applications. Ohio: Charles E Merrill. BAYNE, BS 1997: Irritable bowel syndrome and psychological stress. Johannesburg: Rand Afrikaans University.

BAYNE, BS; STUART, AD \& PRETORIUS, HG 1999: Irritable bowel syndrome and psychological stress. Health SA Gesondheid, 4(1):19-26.

BECK, AT 1976: Cognitive therapy and emotional disorders. New York: International Universities Press.

BEKKER, FJ; HENTSCHEL, U \& REINSCH, M 1993: Attitudes towards illness \& health \& defense mechanisms in psychosomatic patients. (In: U Hentschel; G Smith; W Ehlers \& JG Draguns eds 1993: The concepts of defense mechanisms in contemporary psychology. New York: Springer, pp. 142-169).

BENSON, H 1996: Timeless healing: The power and biology of belief. New York: Scribner.

BENNETT, P 1989: Irritable bowel syndrome. Nursing Times, 83(46):51-53.

BLANCHARD, EB 1993: Irritable bowel syndrome. (In: RJ Gatchel \& EB Blanchard eds 1993: Pschophysiological disorders: Research and clinical applications. Washington DC: American Psychological Association).

BOWLBY, J 1969: Attachment and loss. Volume 3. New York: Basic Books.

BROOM, B 1997: Somatic illness and the patient's other story: A practical integrative mind/body approach to disease for doctors and psychotherapists. London: Free Association.

BUSH, CM 2001: A holistic group psychotherapeutic intervention for the treatment of IBS and its co-morbid depression and anxiety. Johannesburg: Rand Afrikaans University.

CLARKSON, P 1996: The electric and integrative paradigm: Between the Scylla of confluence and the charybdis of confusion. (In: R Woolfe \& W Dryden 1996: Handbook of counselling psychology. London: Sage; p.50).

DOLAN, LM 2000: The treatment of irritable bowel syndrome: A holistic approach. Johannesburg: Rand Afrikaans University.

DROSSMAN, DA 1998: Presidential address: Gastrointestinal illness and the biopsychosocial model. Psychosomatic Medicine, 60:000 - 000 .

DROSSMAN, DA ed. 1994: The Functional Gastrointestinal Dis- orders. Boston: Library of Congress.

DROSSMAN, DA; THOMPSON, WG \& WHITEHEAD WE 1992: Approaching IBS with confidence. Patient Care, 15, 26(13):175178, 183, 187-188.

DROSSMAN, DA; WHITEHEAD, WE \& CAMILLERI, M 1997 : Irritable bowel syndrome: A technical review for practice guideline development. Gastroenenterology, 112:2120-2137.

DROSSMAN, DA; ZHIMING, L; TONER, BB; DIAMANT, NE; CREED, FH; THOMPSON, D; READ, NW; BABBS, C; BARREIRO, M; BANK, L; WHITEHEAD, WE; SCHUSTER, MM \& GUTHRIE, EA 1995: Functional bowel disorders: A multicenter comparison of health status and development of illness severity index. Digestive Diseases and Sciences, 40(5):986-995.

EGAN, G 1994: The skilled helper. Belmont, California: Brooks/ Cole.

ELS, C; GAGIANO, CA; GRUNDLING, H DE K; VAN ZYL, J \& JOUBERT, G 1995: A study of psychiatric illness in patients with irritable bowel syndrome. South African Medical Journal, 85(12):1368-1372.

FARTHING, MJG 1995: Irritable bowel, irritable body, or irritable brain? BMJ, 310:171-175.

GOMBORONE. JE; DEWSNAP, PA; LIBBY, GW \& FARTHING, MJG 1993: Selective affective biasing in recognition memory in the irritable bowel syndrome. Gut, 34:1230-1233.

GREEN, B \& BLANCHARD, EB 1994: Cognitive therapy for irritable bowel syndrome. Journal of Consulting and Clinical Psychology, 62(3):576-582.

GUTHRIE, E; CREED, F; DAWSON, D \& TOMENSON, B 1991: A controlled trial of psychological treatment for the irritable bowel syndrome. Gastroenenterology, 100:450-457.

GUTHRIE, E; CREED, F; DAWSON, D \& TOMENSON, B 1993: A randomised controlled trial of psychotherapy in patients with refractory irritable bowel syndrome. British Journal of Psychiatry, 163:315-321.

KEENEY, BP 1983: Aesthetics of change. New York: Guilford. KELLY, S; HERTZMAN, C \& DANIELS M 1997: Searching for the biological pathways between stress and health. Annual Revue of Public Health, 18:437-62.

KIMBALL, CP 1984: Symptom formation. Psychotherapy and Psychosomatics, 42:56-68.

LAMMERT, M \& RATNER, M 1987: Group treatment of patients with irritable bowel syndrome. Social Work in Health Care, 12(1):67-89.

LATIMER, PR 1983: Irritable Bowel Syndrome. Psychosomatics, 24(3):205-218.

LAZARUS, RS 1993: From Psychological Stress to the Emotions: A History of Changing Outlooks. Annual Revue of Psychology, 44:1-21.

LAZARUS, RS \& FOLKMAN, S 1984: Stress, Appraisal, and Cop- 
ing. New York: Springer.

LEHRER, PM \& WOOLFOLK, RL eds 1993: Principles and practice of stress management. New York: Guildford.

LOESCHEN, S 1998: Systematic training in the skills of Virginia Satir. Pacific Grove: Brooks Cole.

NORCROSS, JC \& GRENCAVAGE, LM 1990: Eclecticism and integration in counselling and psychotherapy: major themes and obstacles. (In: W Dryden and JC Norcross eds 1990: Eclecticism and Integration in Counselling and Psychotherapy. Loughton, Essex: Gale Centre; p.95).

O'CONNOR, WA \& LUBIN, B 1984: Ecological approaches to clinical and community psychology. New York: John Wiley. OSIPOW, H \& SPOKANE, JF 1987: The occupational stress inventory: Professional manual. Florida: Psychological Assessment Resources.

PERT, C; RUFF, MR; WEBER, RJ \& HERKENHAM, M 1985: Neuropeptides and their Receptors: A Psychosomatic Network. Journal of Immunology, 135(2) August:820s-826s.

RICHARDSON, MS 1993: Work in people's lives: A location for counselling psychologists. Journal of Counselling Psychology, 40(4):425-433.

SALT, WB 1997: Irritable bowel syndrome \& the mind-body braingut connection. Ohio: Parkview.

SANDERS, D 1996: Counselling for psychosomatic problems. London: Sage.

SAPOLSKY, RM 1994: Why zebras don't get ulcers: a guide to stress, stress-related diseases, and coping. New York: WH Freeman.

SCHLEBUSCH, L 1990: Clinical Health Psychology: A behavioural medicine perspective. South Africa: Southern Books.

SCHWARZ, SP; BLANCHARD, EB; BERREMAN, CF; SCHARFF, L; TAYLOR, AE; GREENE, BR; SULS, JM \& MALAMOOD, HS 1993: Psychological aspects of irritable bowel syndrome: Comparisons with inflammatory bowel disease and nonpatient controls. Behaviour Research and Therapy, 31(3):297-304.

SIMJEE, AE 1995: Irritable Bowel Syndrome. Gastroenterolgy Forum, August, 1995.

STANLEY, J 2000: Health behaviour, personality and irritable bowel syndrome. Johannesburg: Rand Afrikaans University. TALLEY, NJ 1994: Why do functional gastrointestinal disorders come and go. Digestive Diseases and Sciences, 39(4):673677.

VAN DULMEN, AM; FENNIS, JFM; MOKKINK, HGA; VAN DER VELDEN, HGM \& BLEIJENBERG, G 1994: Doctors' perception of patients' cognitions and complaints in irritable bowel syndrome at an out-patient clinic. Journal of Psychosomatic Research, 38(6):581-590.
WATKINS, AD 1995: Perceptions, emotion and immunity: An integrated homeostatic network. Quarterly Journal of Medicine, 88:283-294.

WEINER, H 1992: Perturbing the organism: The biology of stressful experience. Chicago: University of Chicago.

WHITFIELD, CL 1995: Memory and Abuse. Florida: Health Communications.

WILLIAMS, R; ZYZANSKI, SJ \& WRIGHT, AL 1992: Life events and daily hassles and uplifts as predictors of hospitalization and outpatient visitation. Social Science and Medicine, 34(7):763768. 